\title{
Os Municípios e as AEC: Tendências Descentralizadoras da Política Educativa em Portugal
}

\author{
Municipalities and AEC: Trends of Decentralization in \\ Educational Policy in Portugal
}

\author{
Neusa Castanheira * \\ Manuela Gonçalves \\ Universidade de Aveiro
}

\begin{abstract}
Em Portugal, no período pós-25 de abril de 1974, o município passou a desempenhar um papel crescentemente relevante em matérias educativas. Este papel foi reforçado com a implementação do Programa de Atividades de Enriquecimento Curricular (AEC) numa lógica de sustentar o conceito de Escola a Tempo Inteiro. Neste artigo, analisa-se o projeto das AEC como um contributo para uma descentralização de competências com base no município. Neste contexto, perspetiva-se a implementação do Programa e a ação educativa do município, por um lado, e discutem-se as políticas educacionais de descentralização e desconcentração em Portugal, após o 25 de abril, por outro. Aplicando uma metodologia qualitativa através da realização de entrevistas semiestruturadas em três municípios contíguos, foi desenvolvido um estudo empírico, a partir do qual é possível afirmar que a relação escola-município se encontra claramente reforçada. Contudo, os agentes escolares encaram ainda tal projeto como uma componente extra-escolar traduzindo o receio e o desacordo face a uma real descentralização de competências para os municípios.
\end{abstract}

Palavras-chave: Descentralização, Desconcentração, Municipalização, Atividades de enriquecimento curricular.

In Portugal, in the aftermath of the April 25th (1974) revolution, we witnessed the consolidation of deconcentrated power, in which municipalities began playing an important role in educational matters. This role was reinforced by the implementation of The Basic Education Curriculum Development Program (AEC) to support the concept of Full Time School in which municipalities take responsibility. In this article, we analyze the AEC program as a possible contribution to the development of decentralization, based in the municipality. In this context, we study the implementation of the program and the educational activity of the municipality, on the one hand, and we discuss the educational policies of decentralization and deconcentration in Portugal, after the April 25th (1974) revolution, on the other. Using a qualitative methodology with semistructured interviews which were done in three adjacent municipalities, we developed an empirical study, from which it is possible to conclude that the relation between schools and municipalities appear to be clearly reinforced. However, school agents still acknowledge this program as an extra-schooling element, which reflects their reluctance and disagreement with regard to the actual decentralisation of competencies.

Keywords: Decentralisation, Deconcentration, Municipalization, Enrichment activities curriculum.

*Contacto: nmcastanheira@ua.pt

ISSN: 1696-4713

rinace.net/reice/

revistas.uam.es/reice
Recibido: $\quad 7$ de septiembre 2014

$1^{\text {a }}$ Evaluación: 11 de diciembre 2014

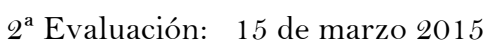

Aceptado: $\quad 11$ de junio 2015 


\section{Introdução}

Em Portugal assistimos, desde a Revolução do 25 de abril de 1974, à emergência de uma diversidade de formas locais e regionais de afirmação de uma possível descentralização de competências. No que respeita à educação, este papel foi reforçado a partir da Lei de Bases do Sistema Educativo e outras disposições legais que preveem a participação e a colaboração dos municípios em áreas educativas antes exclusivamente reservadas ao Estado.

Mais importante do que as aberturas legais tem sido decisiva a crescente colaboração que se vem estabelecendo entre escolas e municípios. A partir da década de 80 do século XX, os municípios têm desempenhado funções em matéria de educação, sobretudo ao nível de encargos financeiros relativos aos transportes escolares e à ação social escolar.

Com efeito, os municípios têm sido das instituições locais mais solicitadas a intervir no campo educativo, quer autonomamente, quer como parceiros do Estado e/ou de instituições privadas. Consequentemente, estamos perante um alargamento do leque de competências municipais em matérias educativas, da institucionalização de uma nova perspetiva local da administração e gestão educativa (Quintaneiro et al., 2012), bem como da afirmação de uma política educativa local (Fernandes, 2003).

Na sequência da implementação das Atividades de Enriquecimento Curricular (AEC), ao abrigo do Despacho n. ${ }^{\circ} 14753 / 2005^{1}$, de 26 de abril, o governo central transferiu para os municípios competências de administração e gestão, no que se refere à tutela pedagógica do Programa, às orientações programáticas, à definição do perfil de formação e habilitações dos professores das AEC, bem como à gestão financeira para o pagamento das despesas inerentes ao Programa. Passado um período de nove anos, várias linhas de orientação têm regido o Programa das AEC e os municípios também já apresentam um longo percurso na tutela do projeto das AEC. Para além disso, o município, com as suas múltiplas intervenções no domínio educativo, apresenta uma função educadora cada vez mais intensificada e que outrora não desempenhava. Assistimos, assim, à abertura de uma nova política educativa com base no município, na qual este assume um papel educativo de liderança e coordenação (Silva, 2006). Esta orientação da política educativa também está relacionada com as novas atribuições que se pretendem conferir às escolas do $1 .{ }^{\circ}$ Ciclo, no sentido de alargar o seu mandato social, indo ao encontro do conceito de Escola a Tempo Inteiro. Assim sendo, as funções da escola passam a incluir outras dimensões e a executar uma panóplia de tarefas, "numa espécie de constante transbordamento" (Pereira e Vieira, 2006), no qual as AEC constituem uma dimensão de relevo.

No entanto, as práticas evidenciam a existência de uma certa diversidade na intervenção educativa dos municípios portugueses, tanto no que diz respeito à execução das competências legalmente atribuídas, como relativamente ao trabalho desempenhado por iniciativa própria.

\footnotetext{
${ }^{1}$ Despacho n. ${ }^{\circ} 14753 / 2005$, de 26 de abril - Cria o Programa de Generalização do Ensino do Inglês no $3 .^{\circ}$ e $4 .^{\circ}$ anos de escolaridade.
} 
Atendendo a esta contextualização, procurámos compreender como três municípios circunjacentes, através da implementação das AEC, se posicionam e atuam perante a transferência de competências efetuada pelo governo central. Pretendemos igualmente compreender e analisar as conceções dos agentes envolvidos (autarcas e diretores/coordenadores de escola) no que diz respeito ao contributo de tal projeto para uma eventual descentralização ou alargamento de competências no domínio da educação com base no município.

Para atingir estes objetivos, utilizámos o método qualitativo, recorrendo a entrevistas semiestruturadas dirigidas a agentes escolares e autárquicos dos três municípios.

\section{O Processo de Descentralização da Educação em Portugal}

Ao refletir sobre o conceito de descentralização, Formosinho (2005a) anota que este se refere a tipos de administração pública menos submissos e dependentes do Estado. Baixinho (2008) acrescenta que a descentralização permite a devolução de poderes de decisão relativos ao Estado para entidades e órgãos autónomos do Estado. Assim sendo, num modelo descentralizado, cabe aos órgãos "regionais" ou "locais", não dependentes hierarquicamente da administração central do Estado, com autonomia administrativa e financeira, a tomada de decisão e competências próprias. De forma distinta, o conceito de desconcentração refere-se à transferência de determinadas competências para os serviços regionais e locais do Estado mas mantendo a decisão no próprio Estado. É um processo que ocorre quando o poder central tem o poder de decisão mas a coordenação e avaliação da execução são concedidas ao poder regional ou local, que por sua vez, terá a função de informar o poder central. Fernandes (2005) define-o como uma forma de centralização, mas mais amenizada, visto que são mantidas as características substanciais da centralização.

Segundo Formosinho (2005a), Portugal adotou desde o século XIX, um sistema administrativo centralizado, seguindo a tradição francesa, designado por "modelo Napoleónico". Contudo, a partir do 25 de abril de 1974, no que diz respeito à educação, tem vindo a aumentar o interesse do Estado pela autonomia da escola e pela participação dos municípios, de outros agentes locais e da sociedade civil (Formosinho, 2000). Na opinião de Pinhal (1997), as tendências descentralizadoras dos sistemas educativos tradicionalmente centralizados, tal como em Portugal, devem-se a inúmeros fatores relacionados com as capacidades de exigência, a reivindicação e intervenção por parte das pessoas resultantes do fácil acesso à informação; a dificuldade por parte do poder central em intervir eficazmente face à crescente complexidade dos subsistemas sociais e com o entendimento de uma maior participação por parte do poder local, tendo em conta a gestão e mobilização apropriada dos seus recursos.

Barreto (1995) acrescenta ainda que algumas das responsabilidades foram transferidas para os municípios e estas modificações vieram introduzir no Sistema Educativo alguns mecanismos de "descentralização funcional". Todavia, as características principais do Sistema Educativo, no que diz respeito à "integração, unificação e centralidade" mantiveram-se, beneficiando apenas de algumas mudanças de intensidade (Barreto, 1995, p. 170). 
Para Formosinho (2005a), as tentativas de descentralização e de desconcentração da administração e gestão das escolas estão referenciadas na Lei de Bases do Sistema Educativo de 1986 (LBSE): "descentralizar, desconcentrar e diversificar as estruturas e ações educativas, de modo a proporcionar uma correta adaptação às realidades, um elevado sentido de participação das populações, uma adequada inserção no meio comunitário e níveis de decisão eficientes" (artigo $3^{\circ}$, alínea g).

Ao analisarmos a LBSE, deparamo-nos com um conjunto de princípios normativos que referenciam a descentralização do Sistema Educativo e o exercício da autonomia pelas escolas. No capítulo VI, (artigo $43^{\circ}$, n. $^{\circ} 2$ e 3 ) faz-se alusão à descentralização e desconcentração de serviços, que será feita através da participação de vários responsáveis no processo educativo. Do mesmo modo, o artigo $45^{\circ}$ (administração e gestão dos estabelecimentos de educação e ensino) faz referência ao funcionamento dos estabelecimentos de ensino em que é orientado segundo uma perspetiva de integração comunitária. Este diploma atribuiu ainda competências em vários domínios à escola, nomeadamente nas atividades de ocupação de tempos livres, atividades de complemento curricular e acompanhamento e apoio aos alunos (artigo $48^{\circ}$ e $52^{\circ}$ ).

Consideramos que, na atualidade, a escola se encontra entre três tendências que são a desconcentração, a descentralização e a intervenção da sociedade civil (Formosinho e Machado, 2005), visto que, por um lado, continua a depender de hierarquias baseadas num sistema desconcentrado e, por outro, tende a ligar-se intimamente aos municípios, que têm vindo a intervir crescentemente em matérias educativas encaminhando-nos para uma eventual descentralização.

Desde a década de 80 do século XX, tem-se vindo a observar, em vários países, uma transformação importante do papel do Estado no que diz respeito à tomada de decisão política e à administração da educação, no sentido de uma transferência de poderes e funções do poder central para o poder local (Barroso, 1999). Este autor acrescenta, ainda, que estas transformações têm vindo a atingir vários países com sistemas políticos bastante diferenciados e com um reforço relevante da autonomia da escola.

O mesmo autor (Barroso, 1999) menciona as várias medidas de política educativa tomadas pelo Sistema Educativo no sentido de reforçar a dimensão local da educação. Destacamos apenas as medidas de desconcentração territorial e funcional de serviços da administração central de criação das Direções Regionais de Educação, o regime de autonomia, administração e gestão, a criação de Conselhos Municipais de Educação, o quadro de transferência de atribuições de competências para os municípios, o quadro de atribuições e competências das comunidades intermunicipais, o quadro de transferência de competências para os municípios em matérias de educação e o regime jurídico do associativismo municipal. Todas estas medidas contribuíram para o desenvolvimento de um sistema de gestão local da educação.

De acordo com a perspetiva de Delgado e Souto (2010), Portugal conserva no poder central as principais tomadas de decisões relacionadas com a educação, havendo, no entanto, uma transferência gradual de poderes, com avanços e recuos, para os municípios. Este processo caracteriza-se por uma possível descentralização e mais próxima da dimensão local, na qual, o autor esclarece a necessidade de haver suficiência financeira e cooperação administrativa como requisitos indispensáveis para uma efetiva autonomia local, tal como capacidade por parte dos municípios em executar as competências educativas delegadas pelo poder central. 
$\mathrm{Na}$ mesma linha de pensamento, Formosinho (2005b, p. 311) caracteriza este tipo de autonomia como sendo uma "autonomia de miséria” na qual está subentendido o facto de poder haver uma "falsa autonomia” atribuída aos municípios; uma autonomia que não pode ser exercida realmente por parte dos municípios por falta de recursos financeiros, humanos e administrativos.

\subsection{O município e a sua ação educativa}

Podemos afirmar, então, que os municípios têm vindo a ganhar um papel relevante em termos da sua ação educativa. Com efeito, para além do que formalmente lhes está atribuído como competências, existe toda uma panóplia de acções, de atividades e de intervenções no domínio da educação, que o demonstram.

Para Fernandes (2005), a importância do município na educação encontra-se associada às políticas educativas municipais, visto que o município deixa, de certa forma, de assumir um papel tradicional de simples executor local da política educativa estatal, passando progressivamente a intervir autonomamente.

Fernandes (1999) distingue três fases, após o 25 de abril de 1974, que revelam um reconhecimento crescente do papel do município na educação. A primeira fase situa-se de 1974 a 1986, durante a qual o município contribui apenas para as despesas públicas com a educação. De seguida, de 1986 a 1996, o município adquire competências educativas, ganhando o estatuto de parceiro social. Finalmente, a partir de 1996, a intervenção municipal na educação é reconhecida. O município passa a participar ao nível da gestão dos interesses públicos educativos, conferida através da avaliação do modelo de gestão definido no Decreto-Lei n. ${ }^{o} 172 / 91^{2}$, de 10 de maio, e posteriormente através da constituição de Agrupamentos de escolas decorrentes das dinâmicas locais. Nesta sequência, começou a desenhar-se um novo regime de autonomia e gestão que abrangesse igualmente o Pré-escolar e $1 .^{\circ}$ Ciclo, medida essa que criaria uma efetiva intervenção municipal e que veio a consubstanciar-se no Regime de Autonomia, Administração e Gestão dos Estabelecimentos Públicos de Educação Pré-escolar e dos Ensinos Básico e Secundário de 1998, que iremos tratar mais à frente.

Assim sendo, segundo Castro (2007), com a aprovação da Constituição de 1976, os municípios puderam afirmar a sua real autonomia enquanto pessoas coletivas públicas, através de órgãos próprios, eleitos pelos munícipes, realizando atribuições igualmente exclusivas. Porém, no que diz respeito ao domínio da educação, esta autonomia e execução das suas funções educativas teve um vagaroso progresso, na medida em que na fase inicial, os municípios detinham principalmente, atribuições referentes aos encargos financeiros (Decreto-Lei n. ${ }^{\circ} 77 / 84^{3}$, de 8 de março em matéria de encargos com

\footnotetext{
2 Decreto-Lei n. ${ }^{\circ}$ 172/91, de 10 de maio - Aprova o regime jurídico de direção, administração e gestão de escola.

3 Decreto-Lei n. ${ }^{\circ} 77 / 84$, de 8 de março - Estabelece o regime da delimitação da coordenação e actuações da administração central e local em mateira de investimentos públicos. Actualmente revogado pela lei $\mathrm{n}^{\circ} 159 / 99$.
} 
investimentos na educação, o Decreto-Lei n. $^{\circ} 299 / 84^{4}$, de 5 de setembro, com os transportes escolares e Decreto-Lei n. ${ }^{\circ} 399-\mathrm{A}^{5} / 84$ de 28 de dezembro com a ação social).

Em 1998, com o Regime de Autonomia, Administração e Gestão dos Estabelecimentos Públicos de Educação Pré-escolar e dos Ensinos Básico e Secundário (Decreto-Lei $n^{\circ}$ 115-A/98 de 4 de maio), surgem as competências concretas dos municípios em matérias educativas. Os municípios passam a ter uma participação nos órgãos de gestão e administração da escola (assembleia) (artigo $8^{\circ}$ ). Esta legislação estabelece ainda os contratos de autonomia (artigo $48^{\circ}$ ), que constituem acordos entre a escola, o Ministério da Educação, a administração municipal e outros parceiros interessados para o desenvolvimento do projeto educativo apresentado pela escola.

Posteriormente, a legislação que confere atribuições de competências aos municípios é referida pela Lei $n^{\circ} 159 / 99^{6}$ de 14 de setembro. Porém, esta legislação conferiu aos municípios, competências a um nível apenas “instrumental”. O artigo $19^{\circ}$ dessa mesma lei define mais especificamente as competências no domínio da educação dos municípios no que se refere à participação no planeamento e na gestão dos equipamentos educativos, à elaboração da carta escolar e criação dos Conselhos locais de educação, ao asseguramento dos transportes escolares e refeições, ao apoio do desenvolvimento de atividades complementares de ação educativa, à participação no apoio à educação extraescolar e na ação social das crianças do pré-escolar e ensino básico bem como na gerência do pessoal não docente do pré-escolar e $1 .^{\circ}$ Ciclo. Esta legislação concede ainda o princípio da subsidiariedade na medida em que tudo o que o município pode fazer de forma mais eficaz não deve ser feito pelo Estado (Castro, 2007).

Em 2003, o Decreto-Lei n. ${ }^{\circ}$ 7/20037, de 15 de janeiro, alterado pelo Decreto-Lei n. ${ }^{\circ}$ 41/2003 ${ }^{8}$, de 22 de agosto regulamenta a criação dos Conselhos Municipais de Educação e aprova o processo de elaboração da Carta Educativa, transferindo, mais uma vez, competências para os municípios. Estes Conselhos Municipais de Educação são nomeados por deliberação da Assembleia Municipal, nos termos propostos pelo município (artigo $3^{\circ}$ ) contribuindo assim para o reforço da descentralização. No artigo $4^{\circ}$ desse mesmo Decreto-Lei estão referenciadas as competências dos Conselhos Municipais de Educação no que toca à coordenação e articulação da política educativa com outras políticas sociais, à elaboração da carta educativa, ao desenvolvimento dos projetos educativos, ao apoio de crianças com necessidades educativas, à organização de atividades de complemento curricular e intervenções no parque escolar.

\footnotetext{
${ }^{4}$ Decreto-Lei n. ${ }^{\circ}$ 299/84, de 5 de Setembro - Regula a transferencia para os muncipios das novas comptencias em materia de organização, fincanciamento dos transportes escolares.

${ }_{5}^{5}$ Decreto-Lei n. ${ }^{\circ}$ 399-A/84 de 28 de dezembro - Regula a transferencia para os municipios das novas competencias em matéria de ação social no dominio dos refeitorios, de alojamento em agregado familiar e de auxílios económicos destinados às crianças da educação pré-escolar e aos alunos do ensino primário e do ciclo preparatório.

${ }^{6}$ Lei n. ${ }^{\circ} 159 / 99$, de 14 de setembro - Lei de transferência de atribuições e competências para as autarquias locais.

7 Decreto-Lei n. ${ }^{\circ} 7 / 2003$, de 15 de janeiro - Regulamenta os conselhos municipais de educação e aprova o processo de elaboração de carta educativa, transferindo competências para as autarquias locais.

${ }^{8}$ Decreto-Lei n. $^{\circ} 41 / 2003$, de 22 de agosto - Primeira alteração ao Decreto-Lei n. ${ }^{\circ}$ 7/2003, de 15 de Janeiro que regulamenta os conselhos municipais de educação e aprova o processo de elaboração de carta educativa, transferindo competências para as autarquias locais.
} 
Em 2008, o Decreto-Lei n. ${ }^{\circ} \quad 75 / 2008^{9}$, de 22 de abril, fortalece a participação, intervenção e contribuição no que diz respeito à constituição dos agrupamentos de escolas e conceção das orientações dos estabelecimentos de ensino bem como à celebração e avaliação de contractos de autonomia das escolas. Posteriormente, em 2012, o novo Decreto-Lei n. ${ }^{\circ} 137 / 2012^{10}$, de 2 de julho, acentua esta ênfase atribuída à municipalização, criando uma nova organização da administração da educação que assenta na descentralização da educação e no desenvolvimento da autonomia, bem como na valorização de cada instituição escolar reconhecida no seu projeto educativo e numa organização pedagógica flexível.

Assim sendo, na opinião de Castro (2007), o município tem uma participação e intervenção incontestáveis no processo educativo, visto que possui um vasto conjunto de competências que dizem respeito à concretização da política educativa definida pelo Estado acrescentando ainda que, estando a atribuir competências na área da educação aos municípios, estamos, igualmente, a contribuir para a territorialização da educação, fomentando a relação íntima entre a escola e o seu meio que lhe é inerente e próprio (comunidade local).

Progressivamente, desde o 25 de abril de 1974, os municípios passam a envolver-se cada vez mais, em matérias escolares e não escolares devido ao facto de possuírem mais recursos e responsabilidade democrática (construção e renovação de estabelecimentos de ensino do $1^{\circ}$ ciclo, transportes escolares gratuitos para os anos de escolaridade obrigatória rede pública de bibliotecas). Contudo, para Fernandes (1996, p. 55), o município permanece um simples parceiro na comparticipação dos custos da educação, não tendo a liberdade, mesmo que limitada, de intervir na sua administração.

Em Portugal, os municípios nem sempre desempenharam esse mesmo papel principal mas, essa ideia veio a impor-se dado que o fundamento da constituição dos municípios, associado ao direito que as populações detêm para se autogovernar, não deixou de estar presente.

\subsection{A inclusão do extraescolar: o programa das $A E C$}

Em 2005, o Governo central cria um programa para o 1..$^{\circ}$ Ciclo do Ensino Básico denominado de Programa das Atividades de Enriquecimento Curricular, após a atividade letiva (a partir das 15h45), isto, através da aplicação do Programa de Generalização do Ensino de Inglês nos $3 .^{\circ}$ e $4 .^{\circ}$ anos de escolaridade ao abrigo do Despacho n. ${ }^{\circ} 14753 / 2005$, de 26 de abril. Este projeto cresce com a vontade de ajudar as famílias na gestão dos horários e dotar as crianças de competências transversais, começando por incluir o ensino do Inglês nos $3 .^{\circ} \mathrm{e} 4 .^{\circ}$ anos de escolaridade. No relatório da CAP (Comissão de Acompanhamento do Programa) em 2006 é referido que até à implementação do Programa das AEC, no ano letivo 2005/2006, somente um quarto das crianças matriculadas no $1 .^{\circ}$ Ciclo do Ensino Básico usufruía, após o terminar das atividades curriculares, de uma panóplia de atividades que enriqueciam as suas aprendizagens e proporcionava-lhes um acompanhamento educativo favorável. Este

${ }^{9}$ Lei n. ${ }^{\circ} 75 / 2008$, de 22 de abril - Aprova o regime de autonomia, administração e gestão dos estabelecimentos públicos da educação pré-escolar e dos ensino básico e secundário.

${ }^{10}$ Decreto -Lei n. ${ }^{\circ} 137 / 2012$, de 2 de julho - Altera a lei n. ${ }^{\circ} 75 / 2008$ de 22 de abril. 
facto só era possível graças ao investimento financeiro das famílias e com recurso a entidades privadas para o efeito.

Com a implementação das AEC, puderam ser promotores desta iniciativa, os municípios, as associações de professores, as associações de pais e os institutos de línguas bem como outras entidades que reúnam os requisitos necessários à apresentação de projetos. Os municípios detêm a primazia sobre as restantes entidades promotoras e surgem como os principais responsáveis passando a atuar em parceria e celebrando protocolos com as escolas ou agrupamentos de escolas, tendo como principais responsabilidades, o recrutamento de professores, a administração e a gestão do programa. Com efeito, NetoMendes e Simões (2007) realçam numa análise ao Relatório Intercalar elaborado pela Comissão de Acompanhamento que os resultados obtidos superaram os objetivos previstos, visto que os municípios adquiriram um papel ativo na aplicação do Programa e são os principais parceiros educativos, sendo estes, $89 \%$ das entidades promotoras e apenas 4,1\% dos Agrupamentos de Escolas, 4,6\% das Associações de Pais e 2,3\% das Instituições Paticulares de Solidariedade Social (IPSS), o são.

Até à data, este Programa tem vindo a ser alterado ao longo dos tempos consoante as necessidades sentidas e avaliações efetuadas.

Em 2006, com o Despacho n. ${ }^{\circ} 12591 / 2006$, de 16 de junho, passam a existir outras atividades para além da obrigatoriedade das atividades do Apoio ao Estudo e do ensino do Inglês para os alunos dos $3 .^{\circ}$ e $4 .^{\circ}$ anos de escolaridade, isto é, a Atividade Física e Desportiva, o ensino da Música, o ensino de outras expressões artísticas, bem como de outras atividades que incidam nos domínios científicos, tecnológico e das Tecnologias da Informação e Comunicação (TIC).

Em 2008, devido ao sucesso alcançado com a implementação do Programa de Generalização do ensino do Inglês nos $3 .^{\circ}$ e $4 .^{\circ}$ anos do $1 .^{\circ}$ Ciclo do Ensino Básico, em 2005, e o lançamento em 2006 do Programa de Generalização do ensino do Inglês e de outras Atividades de Enriquecimento Curricular, o governo visa aperfeiçoar as condições de ensino/aprendizagem no $1 .^{\circ}$ Ciclo do Ensino Básico. O Programa das AEC passa a ser regulamentado por um novo normativo: o Despacho n. ${ }^{\circ} 14460 / 2008^{11}$, de 26 de maio. Neste novo Despacho surgem algumas alterações e reorganizações que dizem respeito à flexibilização dos horários, em que os agrupamentos de escola podem, se for necessário, adaptar o horário da atividade curricular em função das AEC, respeitando e não interferindo na qualidade pedagógica, à abrangência do ensino do Inglês aos $1 .^{\circ}$ e $2 .^{\circ}$ anos de escolaridade, bem como o surgimento de uma Componente de Apoio à Família (CAF) no 1. ${ }^{\circ}$ Ciclo prestada pelas mesmas entidades promotoras das AEC, que se predispõem a assegurar o acompanhamento dos alunos antes e/ou após as AEC, sendo esta, e/ou durante os períodos de interrupção das atividades letivas, desde que as necessidades das famílias o justifiquem.

No ano letivo de 2011/2012, voltam a surgir novas linhas de orientação ao Programa com o Despacho n. ${ }^{\circ} 8683 / 2011$, de 28 de junho. Este Despacho introduz alterações no que diz respeito à flexibilização curricular dos horários, permitindo que ocorra até dois dias por semana não colocando a qualidade pedagógica em causa, bem como, o

${ }^{11}$ Despacho n. ${ }^{o}$ 8683/2011, de 28 de Junho - Altera o Despacho n. ${ }^{\circ} 14460 / 2008$ de 26 de maio, que define as normas a observar no período de funcionamento dos estabelecimentos de ensino, na oferta das atividades de enriquecimento curricular e de animação e de apoio à família. 
surgimento de uma nova atividade de enriquecimento curricular denominada de actividade Lúdico-Expressiva que integra uma ou mais formas de expressão artística com caráter rotativo.

Em 2013, surge o Despacho n. $^{\circ}$ 9265-B/201312, de 15 de julho, que define a obrigatoriedade dos agrupamentos de escolas, enquanto entidades promotoras, afetarem os recursos docentes de quadro que possuam para a realização de uma ou mais AEC. Não sendo entidades promotoras, terão de estabelecer um protocolo com as respetivas entidades promotoras das AEC para esse efeito.

Como temos vindo a observar, com a operacionalização das AEC, os municípios foram adquirindo progressivamente uma posição cada vez mais importante no domínio da educação através das competências delegadas pelo poder central, ocupando, assim, um lugar de que antes estavam afastados.

\section{Orientações Metodológicas}

Com este estudo pretendeu-se compreender a execução das AEC como uma possível tentativa de descentralização da educação de acordo com a transferência de competências para o município nomeadamente na contratação de professores do $1 .^{\circ}$ Ciclo. Atendendo ao objeto de estudo, a metodologia da investigação adotada foi de caráter qualitativo.

O estudo foi realizado, no ano de 2012, entre os meses de janeiro e março, em três municípios portugueses, Município Beirão, Município dos Montes e Município dos Rios. Procurou-se auscultar as perspetivas quer dos autarcas, quer dos dirigentes escolares.

Utilizámos a entrevista semiestruturada como técnica de recolha de informação, tendo a mesma sido aplicada a três Vereadores do Departamento de Educação e três Presidentes em cada um dos municípios investigados. Efetuou-se também este tipo de entrevista a seis dirigentes escolares: dois Diretores dos agrupamentos de escolas e na sua ausência, a quatro Coordenadores do $1 .^{\circ}$ Ciclo de cada agrupamento pertencentes a cada município tendo sido denominados respetivamente de "Agrupamento Beirão", "Agrupamento dos Rios", "Primeiro Agrupamento dos Montes", "Segundo Agrupamento dos Montes", "Terceiro Agrupamento dos Montes" e "Quarto Agrupamento dos Montes". As entrevistas semiestruturadas foram analisadas de acordo com os procedimentos de análise de conteúdo (Moraes, 1999; Quivy e Campenhout, 1998).

\section{Apresentação e Discussão de Resultados}

\subsection{Alargamento de competências no domínio da educação - a voz dos atores}

O tema da descentralização de competências no domínio da educação foi abordado com os vários presidentes dos Municípios da nossa investigação, de forma a procurar saber se o município seria capaz de abranger outros tipos de competências educativas para além daquelas que já possui. Uma das competências diz respeito à contratação de professores do $1 .{ }^{\circ}$ Ciclo pelos municípios.

12 Despacho n. ${ }^{\circ} 9265-\mathrm{B} / 2013$, de 15 de julho - Define normas na oferta de animação e de apoio à família (AAAF), da componente de apoio à família $(\mathrm{CAF})$ e das atividades de enriquecimento curricular (AEC). 
Globalmente, os presidentes dos municípios anotam dificuldades em abranger outras competências educativas, designadamente pela falta de contrapartidas financeiras a esse respeito (quadro 1). Nas suas opiniões, os municípios teriam capacidade para abranger mais competências no domínio da educação, mas consideram as limitações económicas como um entrave à sua concretização. É possível afirmar que estas opiniões vão ao encontro da perspetiva de Formosinho (2005b, p. 311 ), visto que a autonomia decretada acaba por ser uma "autonomia de miséria”, não havendo meios e recursos apropiados para a sua execução. Os inquiridos acrescentam ainda que os municípios deveriam estar adequadamente estruturados, preparados e organizados para tal.

Quadro 1. Entrevistas realizadas aos presidentes dos municípios investigados acerca do alargamento de competências no domínio da educação

\begin{tabular}{|c|c|}
\hline & UNIDADE TEXTUAL \\
\hline Presidente do Município Beirão & $\begin{array}{l}\text { "Mas também se começamos a alargar e a ficar com muitas } \\
\text { funções do Ministério da Educação... Pode correr mal e nem sei } \\
\text { se os professores gostariam muito disso... Mas teria que ser com o } \\
\text { devido acompanhamento financeiro e uma vez que as Câmaras } \\
\text { estariam bem estruturadas para isso [...] Fala-se nisso mas ao } \\
\text { nível das associações de municípios e agora há as comunidades } \\
\text { intermunicipais em que a educação ou outros assuntos são } \\
\text { discutidos nas comunidades intermunicipais." }\end{array}$ \\
\hline Presidente do Município dos Montes & $\begin{array}{l}\text { "O município tem capacidade para abarcar... O Estado Central } \\
\text { gosta de delegar competências e dar-lhe meios nos primeiros anos } \\
\text { e depois retira-lhos e isto cria um desequilibrio estrutural." }\end{array}$ \\
\hline Presidente do Município dos Rios & $\begin{array}{l}\text { "Não, nos moldes em que foram implementadas [...] Não faz } \\
\text { qualquer sentido, tanto mais que só geraria ineficácia e } \\
\text { ineficiência a um processo que funciona bem." }\end{array}$ \\
\hline
\end{tabular}

Fonte: Autores.

Apercebemo-nos, também, que este desacordo relativamente à delegação de outras competências da Educação parece indiciar que os entrevistados consideram o modelo de centralização da Educação atual como sendo um modelo eficaz. Para além disso, os presidentes inquiridos parecem estar conscientes dos limites e dos riscos da tutela dessas competencias por parte dos municipios, na medida em que, nas suas opiniões, os professores do $1 .{ }^{\circ}$ Ciclo poderiam considerar as suas contratações despropositadas, por parte destes. No nosso ponto de vista, encontramos aqui uma certa tensão entre a vontade de os municipios serem órgaos descentralizados e o acréscimo de responsabilidades que isso representa. Por outro lado, a análise destes resultados permite-nos perceber que a municipalização e a privatização constituem assuntos discutidos e atuais, no seio das comunidades Intermunicipais e associações de municipios, tal como refere um dos entrevistados. De facto, para Pinhal (2011), o desenvolvimento do município tem-se fortalecido através do contributo da Associação dos Municípios Portugueses, através do qual os municípios têm estado mais coesos, negociando os diversos desentendimentos com o poder central em matérias de atribuições de competências e ao seu respetivo financiamento.

Estes resultados convergem para a perspetiva de Delgado e Souto (2010), que refere a falta de contrapartidas financeiras como um dos principais entraves à execução das transferencias de competências para os municípios. Como exemplo disso, salientamos ainda a visão de Veiga (2014) que anota que segundo as sucessivas reformas no sentido de proceder a uma maior descentralização em Portugal, a administração local continua a 
deter uma menor parcela, quer da despesa quer da receita pública, que na maioria dos países desenvolvidos.

Por conseguinte, ainda existe falta de consenso nessas matérias, na medida em que uns presidentes dos municípios parecem aceitar e outros rejeitar que tal medida se concretize, tal como aconteceu com o Projeto das AEC. É de salientar que o presidente do Município dos Rios rejeitou a tutela das AEC deixando ao Agrupamento dos Montes a administração e gestão de tal projeto enquanto os presidentes dos outros dois municípios o assumiram.

Este tema foi igualmente abordado com a Coordenadora do 1. ${ }^{\circ}$ Ciclo do Agrupamento Beirão, os dirigentes escolares dos quatro agrupamentos dos Montes (Primeiro, Segundo, Terceiro e Quarto Agrupamento dos Montes), bem como com a Coordenadora do 1. ${ }^{\circ}$ Ciclo do Agrupamento dos Rios, pertencentes respetivamente ao Município Beirão, dos Montes e dos Rios (quadro 2).

Quadro 2. Entrevistas realizadas aos dirigentes escolares dos agrupamentos investigados acerca do alargamento de competências no domínio da educação

UNIDADE TEXTUAL

"Isto a nível da contratação há sempre uma proximidade e temos tendência para proteger alguns grupos. Se for com as regras das autarquias e cada uma tem os seus critérios... Depois cada uma tem as suas e corremos o risco de haver mais injustiças [...] Em termos de gestão e de urbanização... Penso que sim... Em que houvesse umas linhas mestras que são iguais em todo o lado porque podia haver autonomia sim... mas sempre com um pilar base para funcionarmos todos de forma semelhante."

Coordenadora do $1 .^{\circ}$ Ciclo do

Agrupamento Beirão

$\begin{array}{ll}\text { Coordenadora do } 1 .{ }^{\circ} \text { Ciclo do } & \text { "Mas não concordo que outras competências, por exemplo no domínio da } \\ \text { Primeiro Agrupamento dos } & \text { contratação de professores do } 1 .{ }^{\circ} \text { Ciclo e até acho que as AEC deveriam }\end{array}$

Montes passar todas para os agrupamentos."

Coordenadora do $1 .{ }^{\circ}$ Ciclo do "Pode-nos pôr muito em causa a nós. Não sabemos que critérios é que

Segundo Agrupamento dos muitas vezes estão subjacentes a determinadas escolhas e eu acho que isso Montes pode serpreocupante."

Diretor do Terceiro

Agrupamento dos Montes

"Relativamente a essa questão da competência pedagógica, não... O município não teria... Mas mesmo da seleção deveriam ser por parte do agrupamento escolar."

"Todas as que têm são as suficientes, são ao nível do $1 .{ }^{\circ}$ Ciclo... A partir

Diretor do Quarto Agrupamento daí entramos num processo de municipalização da educação, acho que em dos Montes muitos países já deu mau resultado e então é melhor não irmos por aí e acho que assim está bem."

"Não sei se têm capacidade para isso mas talvez consigam mas tenho algumas dúvidas e receios... Há sempre aqui certas cores partidárias que podem causar alguns desconfortos. Agora, se pensarmos em termos de

Coordenadora do $1 .^{\circ}$ Ciclo do Agrupamento dos Rios ideal eu acho que seria o ideal... Em que é o governo que está no terreno e que sabe as necessidades [...] Talvez este projeto tenha sido um começo e uma experiência nesse âmbito, agora houve sítios onde correu bem e outros mal... Se calhar isto foi uma experiência para ver como isto funciona e podermos estar a ir para uma municipalização."

Fonte: Autores.

Todas as opiniões dos dirigentes escolares apontam para o desacordo com a transferência de mais competências educativas para os municípios, nomeadamente competências no domínio do recrutamento dos professores do 1 . $^{\circ}$ Ciclo, visto que consideram que tal facto poderia originar injustiças na forma de contratação segundo 
diferentes critérios e requisitos exigidos, confirmando, de alguma forma, a perspetiva de um dos Presidentes anteriormente inquiridos.

A análise de resultados permite-nos destacar alguns receios e desconfianças na abrangência de outras competências educativas por parte dos municípios, embora seja referido como ideal e atractivo, pelo facto de os municípios possuírem mais competências visto deterem um melhor conhecimento da realidade do seu concelho.

Assim, enquanto uns (Coordenadoras do $1 .^{\circ}$ Ciclo dos Agrupamentos Beirão e dos Rios) concordam com a delegação de competências no domínio da gestão e das infraestruturas escolares nos municípios, defendendo uma certa uniformização dos procedimentos de todos os municípios, para não criar qualquer forma de injustiça, outros (Diretores dos terceiro e quarto agrupamentos dos Montes e Coordenadoras do $1 .{ }^{\circ}$ Ciclo dos primeiro e segundo Agrupamentos dos Montes) consideram que as competências ao nível do $1 .{ }^{\circ}$ Ciclo que os municípios já possuem são suficientes.

Finalmente, enfatizamos a opinião de um dos entrevistados inquiridos ao apontar que a implementação das AEC terá sido a primeira experiência da municipalização da Educação, contribuído, desta forma, para a averiguação dos resultados do funcionamento de um possível municipalização da educação, na medida em que cada município passou a deter mais competências educativas.

Assim sendo, podemos afirmar que se tem gerido uma certa tensão, receios e desconfianças entre o município e a escola, considerando-se assim pertinente refletir sobre a relação que se estabelece entre as duas instituições.

\subsection{A relação escola-município}

De acordo com os resultados obtidos na nossa investigação, alguns municípios parecem rejeitar mais competências no domínio da educação, evidenciando algumas relutâncias face à contratação de professores e aos moldes em que esta se faria. Outros aparentam aceitarem-na, esforçando-se para abranger futuramente outras responsabilidades, caso haja comparticipação financeira para o efeito.

Todavia, se o caráter desconcentrado de competências, evidenciado no Programa das AEC, levar os municípios a assumir um papel importante no seio da educação, tornandoos futuros protagonistas de uma possível descentralização e municipalização da educação, os resultados do nosso estudo indicam algumas resistências face a essa situação. Por um lado, os dirigentes escolares implicados no nosso estudo manifestam o seu profundo desacordo e por outro, os responsáveis políticos dos municípios revelam que nos moldes e estruturação do Programa das AEC, essa municipalização será difícil de se concretizar. Pese embora essa hipótese não ser colocada de parte pelos responsáveis políticos, estes estão conscientes do desagrado que isso poderá causar aos professores. Realçamos a visão de um dos nossos entrevistados que considera este Programa uma forma de, apesar de em pequena dimensão, ser um projeto de início da municipalização do ensino constituindo "a primeira experiência” nesse campo, traduzindo o possível começo de uma futura descentralização da educação com base no município.

Assim sendo, de acordo com os participantes na nossa investigação, a implementação do projeto das AEC em 2005, apesar de constituir uma real e efetiva desconcentração de competências no domínio da educação, concretiza os vários obstáculos observados 
perante uma possível descentralização de competências educativas, relacionados com as limitações económicas, a estruturação e organização dos municípios bem como, as relutâncias e resistências perante uma futura transferência de competências educativas para o poder local.

Esta análise corrobora a perspetiva de Baixinho (2008), para quem o poder central tem vindo a delegar vários processos de administração e gestão educativa que geram tensões entre os diversos agentes pertencentes à comunidade educativa e ao município, constituindo assim uma instabilidade no desenvolvimento local. Este autor acrescenta, ainda, que atualmente o governo central tende a originar um debate entre "centralização estratégica da planificação e da repartição de recursos e descentralização de decisões operacionais" para os municípios e conclui que no seu ponto de vista, as competências transferidas para os municípios são pautadas pelos "constrangimentos na aplicação das competências regulamentadas, na insuficiência de meios humanos e financeiros e na dúbia posição que o município usufrui no sistema educativo" (Baixinho, 2008, p 249250). Assim sendo, de uma forma contraditória a transferência de competências para os municípios baseia-se no princípio da racionalização, tendo em conta que é o mesmo fundamento da recentralização.

No entanto, para Carvalho (2014), Portugal reflete apenas algumas formas de descentralização atendendo a uma desconcentração de poderes efetiva passando pela transferência de algumas competências do poder central para o poder local. Na mesma linha de pensamento, Cerca (2008) anota, mais uma vez, que há alguma incerteza quanto aos moldes da regulamentação efetuada às novas atribuições em educação, na medida em que não se consegue perceber se corresponde a uma efetiva descentralização de competências ou apenas a uma mera transferência de encargos. Na sua perspetiva, os municípios já adquiriram um papel importante em matérias educativas tendo em conta a sua participação ativa, embora esta esteja limitada pelas formas de centralização do poder, pelo desenvolvimento concelhio que lhe é inerente, bem como pelo tipo de população que o ocupa.

De certa forma, os resultados obtidos no nosso estudo retratam o envolvimento crescente, por parte dos municípios, em matérias de educação, na medida em que os municípios estariam dispostos a ter mais competências em matérias escolares caso houvesse as devidas contrapartidas financeiras para esse efeito.

\section{Principais Conclusões}

Progressivamente, desde o 25 de abril de 1974, os municípios têm desempenhado um papel significativo no desenvolvimento em todo o sistema educativo. Para além do que formalmente lhes está atribuído como competências, há toda uma serie de ações, de atividades e de intervenções que o demonstram.

A gestão e administração das escolas exercem-se num clima de participação democrática de vários interventores em que o sistema educativo contribui com as suas estruturas administrativas que garantem uma interligação com a comunidade, mediante adequados graus de participação dos alunos, das famílias e encarregados de educação mas também dos municípios, de entidades representativas das atividades sociais, económicas e culturais e ainda de instituições de caracter científico. 
A implementação das AEC intensificou a ação do município e ligou-o intimamente a questões que se prendem com o recrutamento e a contratação de professores, a gestão e a administração escolar, a gestão financeira e outras preocupações relacionadas com as políticas educativas de territorialização.

O presente estudo permitiu conhecer as perspetivas quer dos responsáveis políticos quer dos dirigentes escolares face à execução das AEC colocando esta possível e eventual descentralização de competências educativas e municipalização do ensino no centro das preocupações dos responsáveis políticos no domínio da educação. As perspetivas dos responsáveis políticos apontam para uma possível aceitação da descentralização de competências caso haja, segundo eles, uma comparticipação e estruturação do Programa das AEC adequadas, contrapondo-se claramente às perspetivas dos docentes, que manifestam o seu profundo descordo com esse facto podendo, de acordo com estes, originar injustiças e condenar um sistema educativo centralizado que tem funcionado bem até hoje. De acordo com Lima (2015), a atribuição de maiores responsabilidades e poderes efetuada com menos recursos financeiros influencia decisivamente o exercício de novas responsabilidades, ficando estas dependentes não apenas da vontade política municipal como também da capacidade económica de cada município.

A problemática da descentralização e municipalização do ensino tem sido cada vez mais estudada em Portugal, sendo de realçar a aproximação dos resultados obtidos no nosso estudo com os resultados de outros estudos realizados acerca desta temática ao nível nacional. No estudo de Carvalho (2012), à semelhança do nosso estudo, os docentes manifestam o seu desacordo com a transferência de competências para os municípios ao nível da gestão do pessoal docente, receando que haja uma perda de autonomia por parte das escolas e que se gere conflitos na relação escola-município. Apenas parecem reconhecer vantagens à contribuição do município ao nível social, logístico e das infraestruturas. Do mesmo modo, no estudo anteriormente referido, os responsáveis políticos anotam a necessidade de definir políticas educativas ao nível local, sendo que ao município seja atribuído competencias em matérias educativas ao nível local devido à sua íntima ligação com o poder central. Do mesmo modo, são vários os estudos que chegam a conclusões análogas, nomeadamente no que se refere à falta de recursos humanos e técnicos por parte dos municípios para fazer face à realidade complexa que exige a organização e gestão do ensino, à consolidação da ação municipal no âmbito das AEC, bem como à existência de uma política efetiva de descentralização e municipalização do ensino para esse efeito (Martins, 2007; Baixinho, 2009; Esteves, 2009; Pereira, 2010; Lopes, 2012; Queirós, 2012 e Neves, 2012).

No panorama internacional, destacam-se inúmeros trabalhos sobre o processo de descentralização e municipalização do ensino, nomeadamente por investigadores do espaço ibero-americano, através dos quais adquirimos um melhor conhecimento sobre o estabelecimento desses processos nesses países (Casassus, 1990; Soares, 2005; Souza e Faria, 2004; Bitar, 2006; Novaes e Fialho, 2010; Vieira, 2010; Rodrigues e Sicca, 2013 e Krawczyk e Vieira, 2014).

Por fim, salientamos que Portugal se identifica também com esta panorâmica internacional, emergindo assim vários estudos comparativos acerca da descentralização na educação, sustentando a tese de que vários países tendem a copiar modelos ou soluções existentes noutras realidades (Grancho, 2008; Delgado e Souto, 2010, Sousa et al., 2013 e Carvalho, 2014). 


\section{Referências}

Baixinho, A.F. (2008). Educação e autarquias em Portugal. Lógicas de ação do poder autárquico em face do poder central e dos micropoderes locais. EccoS Revista Científica, 1O(1), 233-254.

Baixinho, A. F. (2009). O Município e a construção da política local de educação: estudo de caso numa autarquia do oeste. EccoS Revista Científica, 11(2), 433-455.

Barreto, A. (1995). Centralização e descentralização no sistema educativo. Análise Social, 1(130), 159-173.

Barroso, J. (1999). A escola entre o local e o global. Perspetivas para o século XXI. O caso de Portugal. En J. Barroso (Org.). A escola entre o local e o global. Perspetivas para o século XXI (pp. 129-142). Lisboa: Educa.

Bitar, M.S. (2006). A política educacional francesa em foco: um breve estudo sobre o processo de descentralização da educação na França. Pro-posições, 17(2), 175-194.

CAP (2006). Comissão de acompanhamento do programa (2006). Relatório intercalar de acompanhamento das atividades de enriquecimento curricular-programa de generalização do ensino do inglês nos $3^{\circ}$ e $4^{\circ}$ anos e de outras atividades de enriquecimento curricular no $1^{\circ}$ ciclo do ensino básico. Lisboa: Ministério da Educação.

Carvalho, M.I. (2012). A (des) centralização e a intervenção dos municípios na educação: a percepção dos diversos actores educativos. Dissertação de Mestrado não publicada, Universidade Católica Portuguesa, Viseu.

Carvalho, E.J. (2014). Reformas na administração educacional: uma análise comparada entre Brasil e Portugal. Revista Portuguesa de Educação, 27(1), 29-54.

Casassus, J. (1990). Descentralização e desconcentração educacional na América Latina: fundamentos e crítica. Cadernos de Pesquisa, 74, 11-19.

Castro, C.S. (2007). Administração e organização escolar: o direito administrativo da escola. Porto: Porto Editora.

Cerca, I. (2008). Poder Local e educação: que relação? Cadernos do observatório dos poderes locais, 13, $1-24$.

Delgado, P. e Souto, P.M. (2010). As competências educativas locais na Península Ibérica: legislação educativa e normativa municipal de Espanha e Portugal. Revista Iberoamericana de Educación, 54(3), 14-38.

Esteves, T. (2009). A descentralização da administração da educação: as autarquias locais enquanto promotoras do programa das actividades de enriquecimento curricular no $1^{\circ} \mathrm{CEB}$. Dissertação de Mestrado não publicada, Faculdade de Psicologia e de Ciências da Educação, Universidade de Lisboa, Lisboa.

Fernandes, A.S. (1996). Os municípios portugueses e a educação. As normas e as práticas. En J. Barroso e J. Pinhal (Org.), A Administração da educação. Os caminhos da descentralização. Atas do seminário do fórum português de administração educacional (pp. 113-124). Lisboa: Edições Colibri.

Fernandes, A.S. (1999). Os municípios portugueses e a educação: entre as representações do passado e os desafios do presente. En J. Formosinho, A.S. Fernandes, M. Sarmento e F.I. Ferreira (Eds.), Comunidades educativas. Novos desafios à educação básica (pp. 159-180). Braga: Livraria Minho.

Fernandes, A.S. (2003). Descentralização da Administração Educacional. A emergência do município como interventor educativo. En L.L. Dinis e N. Afonso (Eds.), Atas do $2^{o}$ congresso nacional do fórum português de administração educacional "a escola entre o estado e o 
mercado: o público e o privado na regulação da educação” (pp. 83-96). Lisboa: Fórum Português de Administração Educacional.

Fernandes, A.S. (2005). Descentralização, desconcentração e autonomia dos sistemas educativos: uma panorâmica europeia. En J. Formosinho, A.S. Fernandes, J. Machado e F.I. Ferreira (Eds.), Administração da educação. Lógicas burocráticas e lógicas de mediação (pp. 53-87). Lisboa: Edições Asa.

Formosinho, J. (2000). A autonomia das escolas. Lógicas territoriais e lógicas anifitárias. En J. Machado, A.S. Fernandes e J. Formosinho (Coords.), Atas do seminário autonomia contratualização e município (pp. 45-52). Braga: Centro de Formação de Associação de Escolas Braga Sul.

Formosinho, J. (2005a). Centralização e descentralização ma administração da escola de interesse publico. En J. Formosinho, A.S. Fernandes, J. Machado e F.I. Ferreira (Coords.), Administração da educação. Lógicas burocráticas e lógicas de mediação (pp. 13-87). Lisboa: Edições ASA.

Formosinho, J. (2005b). A construção da autonomia das escolas: lógicas territoriais e lógicas afinitárias. En J.Formosinho, A.S. Fernandes, J. Machado e F.I. Ferreira (Coords.), Administração da educação. Lógicas burocráticas e lógicas de mediação (pp. 307-319). Porto: Edições ASA.

Formosinho, J. e Machado, J. (2005). A administração da escola de interesse público em Portugal - Políticas recentes. En J.Formosinho, A.S. Fernandes, J. Machado e F.I. Ferreira (Coords.), Administração da educação. Lógicas burocráticas e lógicas de mediação (pp. 115-137). Lisboa: Edições Asa.

Grancho, J. (2008). A autonomia das escolas em Portugal. Quadro de desenvolvimento e influências internacionais. Foro de Educación, 6(10), 231-244.

Krawczyk, N. e Vieira, V. (2014). Uma perspectiva histórico-sociológica da reforma educacional na América Latina: Argentina, Brasil, Chile e México nos anos 1990. Revista Brasileira de Educação, 19(57), 513-516.

Lima, L.C. (2015). O programa "Aproximar Educação", os municípios e as escolas: descentralização democrática ou desconcentração administrativa. Questões Atuais de Direito Local, 5, 7-24.

Lopes, E.G. (2012). A descentralização do ensino: vontade do poder central ou exigência do poder local. Dissertação de Mestrado não publicada, Universidade Aberta, Lisboa.

Martins, H.M. (2007). Os municípios e a educação: estudo das modalidades de gestão das AEC. Dissertação de Mestrado não publicada, Universidade de Aveiro, Portugal.

Moraes, R. (1999). Análise de conteúdo. Revista da Educação, 22, 37-49

Neto-Mendes, A. e Simões, R. (junio, 2007). A Participação dos municípios na educação: subsídios para o estudo das políticas de descentralização em Portugal. Comunicação apresentada no $V$ Congresso luso-brasileiro de política e administração da educação - por uma escola de qualidade para todos. Porto Alegre, Brasil.

Neves, M. (2012). A administração municipal da educação: o caso das atividades de enriquecimento curricular num município do leste da NUT III, alto Trás-os-Montes. Dissertação de mestrado não publicada, Escola Superior de Educação, Bragança.

Novaes, I.L. e Fialho, N.H. (2013). Descentralização educacional: características e perspectivas. Revista Brasileira de Política e Administração da Educação, 26(3), 46-59.

Pereira, H. e Vieira, M.C. (2006). Entrevista pela educação com António Nóvoa. Saber (e) Educar, 11, 111-126. 
Pereira, M.R. (2010). Municípios e educação em Portugal: um processo de "municipalização"? Dissertação não publicada, Universidade de Aveiro, Portugal.

Pinhal, J. (1997). Os municípios e a descentralização educacional em Portugal. En A. Luís, J. Barroso e J. Pinhal (Eds.), A administração da educação: investigação, formação e práticas (pp. 177-195). Lisboa: Fórum Português de Administração Educacional.

Pinhal, J. (2011). A construção do sistema educativo local em Portugal: uma história recente. Revista Pensamento, 6(12), 13-27.

Pinho, L. (2012). A descentralização de atribuições e competências para as autarquias locais em matéria de educação. Dissertação de Mestrado não publicada, Universidade do Minho, Portugal.

Queirós, C.F. (2012). A organização das atividades de enriquecimento curricular. Dissertação de Mestrado não publicada, Universidade de Aveiro, Portugal.

Quintaneiro, A., Mendonça, A. e Bento, A. (2012). A autonomia das escolas básicas do $1 .^{\circ}$ ciclo com pré-escolar da região autónoma da madeira, da teoria à prática. Comunicação apresentada no VII Simpósio de organização e gestão escolar. Universidade de Aveiro, Portugal.

Rodrigues, A. e Sicca, N.A. (2013). O processo de municipalização dos anos iniciais do ensino fundamental: decorrencias na gestão do currículo. Nuances. Estudos sobre Educação, 24(2), $33-48$.

Silva, F. (2006). A autarquia como promotora da política educativa local. O caso de um município. Dissertação de Mestrado não publicada, Universidade Aberta, Lisboa.

Soares, M. (2005). A descentralização do ensino no Brasil e a implementação dos sistemas municipais de ensino: Razões e determinações. Dissertação de Mestrado não publicada, Universidade Federal do Paraná, Curitiba.

Souza, D. e Faria, L. (2004). Reforma do estado, descentralização e municipalização do ensino no Brasil: a gestão política dos sistemas públicos de ensino pós-LDB 9.394/96. Ensaio, X, 925-944.

Souza, D., Castro, D. e Rothes, L. (2013). Políticas de descentralização da educação no Brasil e em Portugal: avanços e recuos da desconcentração de poderes. Revista Portuguesa de Educação, 26(2), 7-33.

Veiga, L. (2014). Descentralização orçamental: questões de autonomia e responsabilização. NIPE Working Papers Series, 17, 145-177.

Vieira, S.L. (2010). Poder local e educação no Brasil: dimensões e tensões. Revista Brasileira de Política e Administração da Educação, 27(1), 34-56. 